\title{
System for Control of the Physical Development and the Specific Capability of University Students Training Basketball in Turkey
}

\author{
Albay Faruk ${ }^{*}$, Yazarer Ilkay \\ School of Physical Education and Sport, Gaziosmanpaşa University, Turkey
}

\begin{abstract}
Copyright $\bigcirc 2018$ by authors, all rights reserved. Authors agree that this article remains permanently open access under the terms of the Creative Commons Attribution License 4.0 International License
\end{abstract}

\begin{abstract}
The aim of the study is to cultivate the educational process of physical education and sport in the universities in Turkey by discovering the features of the physical development, physical preparation and the specific technical-tactical preparation of the students, engaging with basketball and the elaboration of a system for control and evaluation of the basic signs of the specific workability. Research of the condition of the problem for physical development and the specific workability of the 69 students from 5 universities in Turkey, and comparative analysis of the physical development, the special physical and specific technical-tactical preparation of the basketball players uncover the factor structures and identify the basic factors for physical development and the specific workability of the basketball players who are the students in the different universities of Turkey. The factor structure of the physical development and the specific workability of the students from the basketball teams is based on 5 basic factors, which explain high percent $(70,77 \%)$ of the starting dispersion of the researched occurrence. The first and the most important factor defines the significance of morphological signs which influence positively on the rapidity of movement and the speed endurance of the basketball players. Non-homogeneity is observed regarding the level of development of the functional capacity of the chest and the ability of the basketball players from the universities to lead the ball with high speed; the rest of the researched indicators are relatively stable, and the researched aggregate - relatively homogeneous regarding the signs, which these indicators carry information about. The evaluation of the body mass is in the zone of the norm, in general.
\end{abstract}

Keywords Physical Education, Students, Basketball, Physical Development, Training

\section{Introduction}

The cultivation of the educational-training process of the students from the profiled groups of the different sport disciplines is tightly connected to the learning of the features of the different motor activities. This is why there is a need to conduct researches periodically and to uncover the basic factors and tendencies for this development which is an objective predisposition for a deeper understanding in the essence of the occurrence. The goal is to improve the preparation of the young people and to increase the effectiveness of the training work which they are doing.

The control is part of the cognitive activity of the person[7] or the cognitive process[8], where the information is stored and where the real condition of an object (system), considering its targeting (planned in advance) development and cultivation, is evaluated. It is known that the system for control in the sport includes three subject fields; measurement, evaluating, optimizing $[7,8,9]$. These are three interlinked subsystems of control, which provide the needed information for the management of the training and the competition processes [3].

The summary effect on the training loading is characterizing with cumulating in the organism of the athlete of "traces, reflections", which lead to permanent, resistant characteristics of the general and the special workability [9]. In the field of the sport science and practice the testing [10] has a significant role and presence in the educational-training and in the searching activities, in its diversity of specially selected and standardized motor activities. By testing in sport, from one side, we can registrate a certain condition of some abilities or characteristics of the researched object and from the other side this condition could be compared to some of the criteria, established earlier, i.e. to be evaluated. 
It is one of the desired goals of basketball players, regardless if their playing position is guard, forward or center to improve their jumping ability, in addition to achieving a high level of proficiency in other defensive and offensive acts they have to perform during the game [5].

Detection of the determinative factors of team performance is so important not only in providing exercise effectiveness but also developing game strategies and building up team compositions [4]. Here it is at this point the normative tables allow easy and fast evaluation of the condition of each sign, carrying information about the physical development, the special physical and the specific technical-tactical preparation the researched aggregate.

\section{Materials and Methods}

\section{Organization of the Research}

Subject of the research: physical development and specific workability of the basketball students from the universities in Turkey.

Object of the research: the signs of the physical development, the special physical and the specific technical-tactical preparation of students in the universities.

Contingent of the research: 69 students from 5 universities included in the organized basketball activities.

\section{Description of the Tests (Indicators)}

10: $20 \mathrm{~m}$ sprint - after sound signal, they make two runs from $20 \mathrm{~m}$. The best achievement is respected

11: Running between stands the performer is moving in equilateral triangle with length of the sides $10 \mathrm{~m}$ (Fig.1).

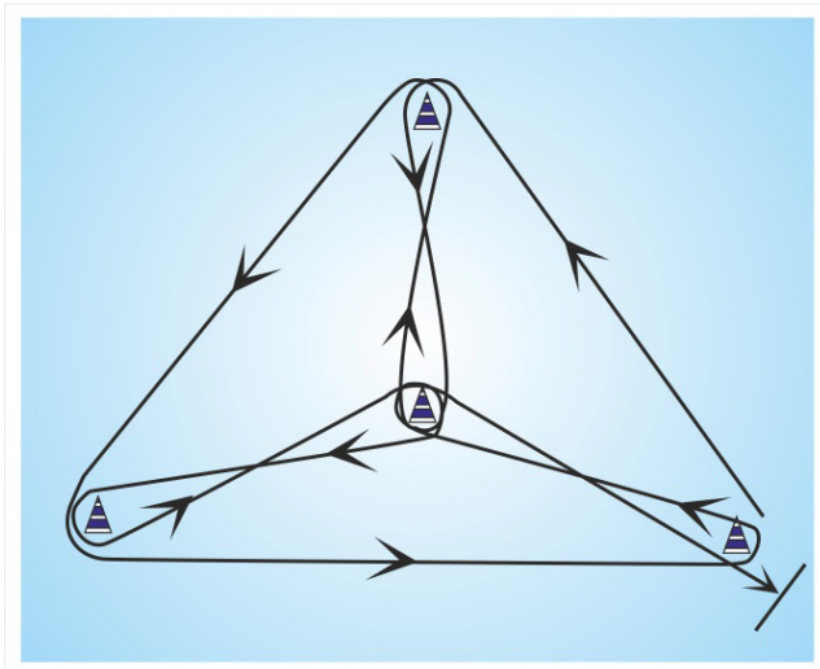

Figure 1. Running way between stands

12: Vertical jump - they measure the height with stretched arm, and after this the researched person squats, performs swish with the hands and jumps with two legs from place. They respect the reached height. The difference between the two indicators gives the pure jump.

13: Triple jump - they perform a swish with hands forwards, down and backwards, which is done together with pulsing of the legs, followed by backwards swish of the hands from down to forward and up and jump with the two legs up and forward. Then there is thrusting from the ground with one of them and then with the other leg and landing on the two legs. They respect the distance from the starting line to the last trace, left by the jumping person. And better achievement is respected.

14: Throwing a medicine ball - the person who is performing is sitting on a chair, with his back to the direction of the throwing. The ball is thrown backwards through the head. They measure the distance from the line of the rear legs of the chair to the place where the ball touches the ground. They do this twice and respect the better achievement.

15: Sit ups - starting position- occipital lying position with knees, constricted to $90^{\circ}$, the feet are opened on the width of the shoulders. The hands are placed on the nape with elbows aside. A partner is holding the ankles and fixes the feet on the ground. There should be a one fist distance between the chin and the chest during the whole time(30s.)

16: "Shutter"running - short sprints with the change of the direction (Fig.2). They run always facing forward. The people go three lengths $(252 \mathrm{~m})$ on the playground.

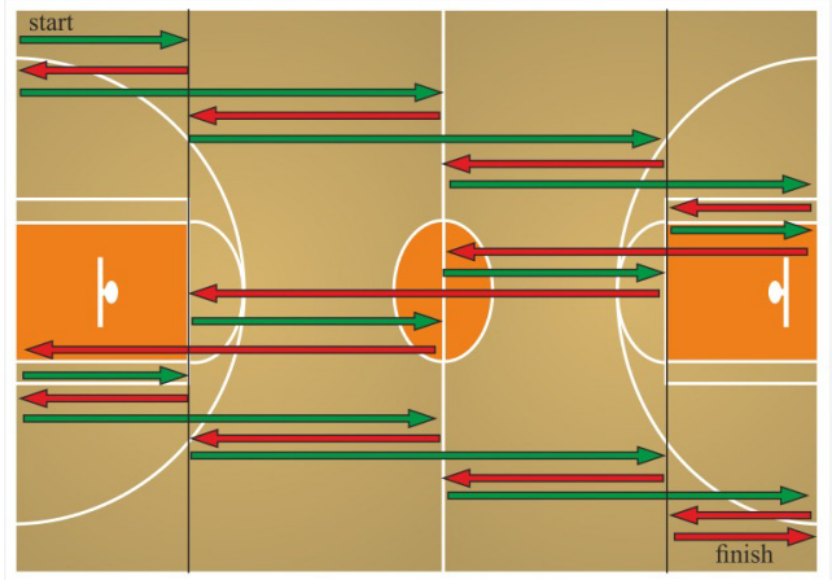

Figure 2. "Shutter" running direction

17: Eights with dribbling- the steps are on the line of the shoulders. After a signal, they perform dribbling with right hand, aside from the right leg, then they do a crossed dribbling with devolving the ball from the back to the forward between the legs, crossed dribbling from back to forward between the legs to the right hand and others. They count each thump on the ground, performed without breaking the certain sequence of the movements (30s). It is performed twice and respected the beter. 18: Leading the ball between stands - the distance is run while they lead a ball (Fig.1)

19: Index of leading the ball - differences between the achievements from test № 18 and test № 11, and it is reported. 
20: Defensive movement - they perform this around a square with a $5 \mathrm{~m}$ side, and they put stands on the corners (Fig.3). They perform sprint on one of the sides, they do a side movement with defensive stand on the second one, they run with their back on the third one and right after that they go back in the opposite direction for the same way until the starting position.

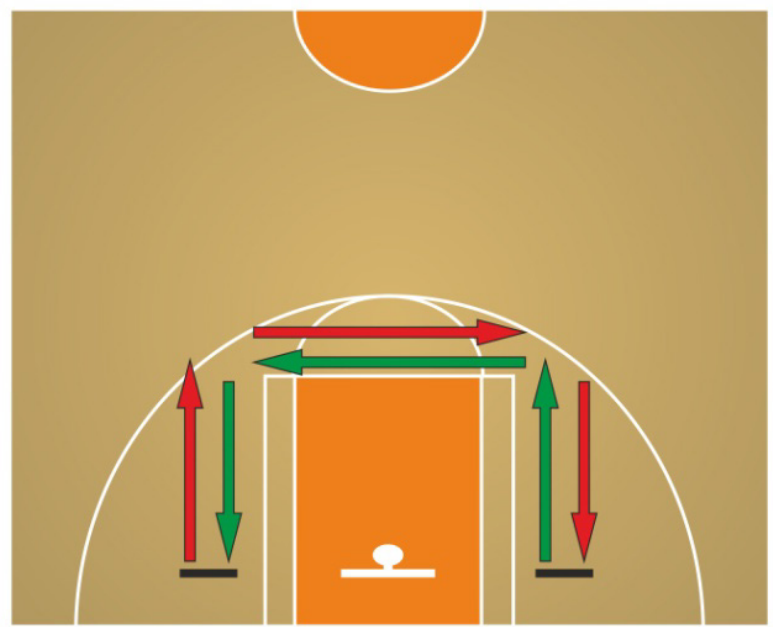

Figure 3. Defensive Movement

21 and 22: Speed shooting with movement time and coefficient -they perform an elusion with leading the ball, followed by shooting in a basket in movement, successively for each of the three stands, put on the line for 3 points(Fig.4) They perform two rounds (6 shoots).

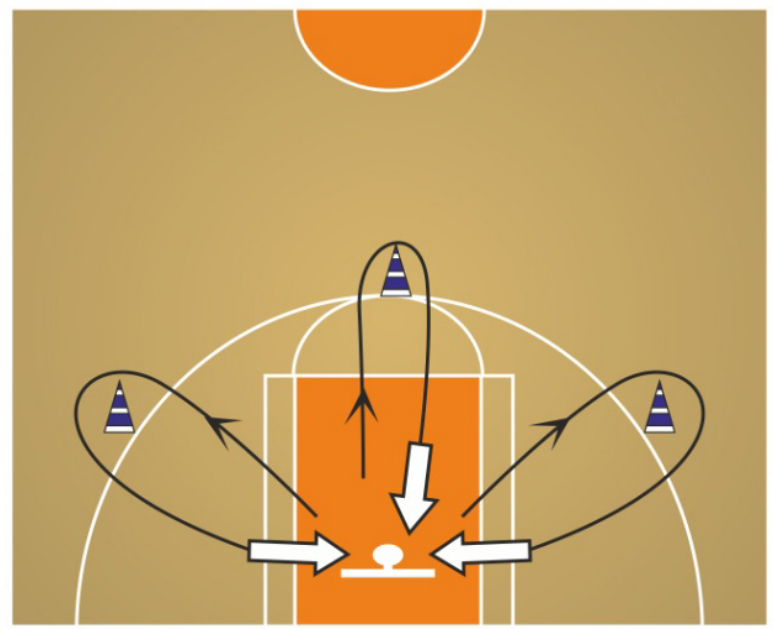

Figure 4. "Speed shooting" movement way
"On the first round the leading and the shooting are done with the hand which they use the most, and on the second round with the opposite hand. They respect the time for performance (ind.21) and the number of successful strikes in the basket. They measure the coefficient of effectiveness of the speed shooting in movement (ind.22), as the time for performance is divided on the number of thee successful strikes in the basket

23: Shooting with jump and feeder - they perform 3 series with 10 shoots in the basket from 3 positions: Perpendicular to the board; under $45^{\circ}$ angle to the board and under $0^{\circ}$ angle to the board. The positions could be situated in the left or the right half of the playground. They work in couples (shooter and feeder). After each series the two of them are changing their functions. The shooting is performed from $5 \mathrm{~m}$ distance from the projection of the center of the ring on the terrain.

24: Penalty hits - \% successful - they work in couples. They perform 10 series of 2 penalty hits ( 20 in total) with a feeder. They esteem the number of the successful penalty hits. As a result from the test, they write the relative part (in \%) of the successful hits in the basket, to all penalty hits performed.

\section{Statistical Methods for Data Analysis}

Factor analysis - for the unfolding of the factor structure of the physical development, the special physical and specific technical-tactical preparation of the students, engaged with basketball in the universities in Turkey.

Sigmal method for evaluation - For evaluation of the condition of the researched signs of the specific workability. On the basis of the average for the researched aggregates level (25p.) for each signs there are normative signs elaborated to evaluate the special physical and the specific technical-tactical preparation of the basketball students.

\section{Findings}

The results of the variational analysis of the starting information from the conducted sport-pedagogical testing generally for the whole researched aggregate of basketball students in different universities in Turkey, are presented in table 1 . 
Table 1. Average values and varieties of the indicators

\begin{tabular}{|c|c|c|c|c|c|c|c|c|}
\hline № & Indicators & $\mathrm{X}$ & $\mathrm{S}$ & $\mathrm{V}$ & $\min$ & $\max$ & As & Ex \\
\hline 1 & Height & 189,86 & 9,65 & 5,08 & 173 & 208 & $-0,09$ & $-1,18$ \\
\hline 2 & Weight & 86,78 & 14,00 & 16,13 & 62 & 120 & 0,55 & $-0,07$ \\
\hline 3 & Body Mas Index (BMI ) & 23,94 & 2,24 & 9,36 & 20,02 & 29,8 & 0,46 & 0,22 \\
\hline 4 & Stretch & 191,16 & 10,34 & 5,41 & 168 & 212 & $-0,17$ & $-0,73$ \\
\hline 5 & Length of upper limb & 84,93 & 8,51 & 10,02 & 66 & 100 & $-0,36$ & $-0,92$ \\
\hline 6 & Length of lower limb & 114,22 & 7,38 & 6,46 & 98 & 127 & $-0,14$ & $-0,89$ \\
\hline 7 & Lenght of palm & 20,84 & 1,43 & 6,85 & 17 & 25 & 0,41 & 0,76 \\
\hline 8 & Length of foot & 28,28 & 1,64 & 5,78 & 25 & 32 & 0,21 & $-0,51$ \\
\hline 9 & Chest -respiratory differences & 5,59 & 2,79 & 49,90 & 2 & 15 & 1,64 & 3,33 \\
\hline 10 & $20 \mathrm{~m}$ sprint & 3,12 & 0,20 & 6,49 & 3,68 & 2,64 & 0,08 & 0,33 \\
\hline 11 & Running between stands & 20,82 & 1,68 & 8,06 & 24,89 & 18,12 & 0,37 & $-0,41$ \\
\hline 12 & Vertical jump & 61,75 & 8,83 & 14,30 & 37 & 77 & $-0,36$ & $-0,10$ \\
\hline 13 & Triple jump & 6,76 & 0,57 & 8,40 & 5,72 & 8,44 & 0,41 & $-0,27$ \\
\hline 14 & Throwing a ball - backwards & 12,51 & 1,93 & 15,44 & 7,95 & 16,58 & 0,17 & $-0,07$ \\
\hline 15 & Sit-ups & 29,30 & 5,03 & 17,17 & 17 & 41 & $-0,05$ & $-0,53$ \\
\hline 16 & "Shutter" running & 65,34 & 4,37 & 6,69 & 78 & 58,05 & 0,72 & 0,35 \\
\hline 17 & Eigts & 54,94 & 10,51 & 19,13 & 32 & 72 & $-0,10$ & $-0,97$ \\
\hline 18 & Leading between stands & 21,86 & 1,85 & 8,47 & 27,71 & 18,35 & 0,42 & 0,30 \\
\hline 19 & Index for leading of the ball & 1,04 & 0,98 & 94,70 & 4,69 & 0 & 1,65 & 2,84 \\
\hline 20 & Movement in defense & 9,38 & 1,14 & 12,19 & 12,05 & 7,05 & $-0,31$ & $-0,22$ \\
\hline 21 & Shooting in movement - $\mathrm{t}$ & 32,42 & 1,92 & 5,91 & 38,18 & 28,78 & 0,73 & 0,09 \\
\hline 22 & Shooting in movement - coeff. & 6,65 & 1,64 & 24,63 & 12,04 & 4,79 & 1,81 & 3,33 \\
\hline 23 & Shooting from position, feeder & 57,10 & 11,26 & 19,72 & 23,33 & 76,67 & $-0,43$ & 0,14 \\
\hline 24 & Penalty hits & 72,25 & 12,88 & 17,82 & 35 & 95 & $-0,75$ & 0,74 \\
\hline
\end{tabular}

The physical development and the specific workability of the students from the Turkish basketball are created from 5 basic factors which are explaining the high percent of the starting dispersion of the researched occurrence (Table 2). 
System for Control of the Physical Development and

the Specific Capability of University Students Training Basketball in Turkey

Table 2. Factor structure of the physical development and the specific workabilities

\begin{tabular}{|c|c|c|c|c|c|c|c|c|}
\hline № & Indicators & $\mathrm{I}$ & II & III & IV & $\mathrm{V}$ & $\mathrm{h}^{2}$ & $1-h^{2}$ \\
\hline 1 & Height & 0,877 & 0,240 & $-0,241$ & $-0,004$ & $-0,081$ & 0,891 & 0,109 \\
\hline 2 & Weight & 0,898 & 0,156 & 0,119 & $-0,193$ & 0,002 & 0,883 & 0,117 \\
\hline 3 & BMI & 0,573 & 0,033 & 0,433 & $-0,319$ & 0,086 & 0,627 & 0,373 \\
\hline 4 & Stretch & 0,852 & 0,340 & $-0,181$ & $-0,175$ & $-0,066$ & 0,910 & 0,090 \\
\hline 5 & Length of the upper limb & 0,658 & 0,544 & 0,145 & 0,014 & $-0,100$ & 0,760 & 0,240 \\
\hline 6 & Length of the lower limb & 0,813 & 0,411 & $-0,084$ & 0,188 & $-0,026$ & 0,874 & 0,126 \\
\hline 7 & Length of the palm & 0,773 & 0,385 & 0,048 & $-0,050$ & 0,001 & 0,750 & 0,250 \\
\hline 8 & Length of the foot & 0,849 & 0,308 & $-0,056$ & 0,003 & $-0,135$ & 0,837 & 0,163 \\
\hline 9 & Respiratory difference & 0,272 & 0,383 & $-0,111$ & 0,165 & 0,222 & 0,309 & 0,691 \\
\hline 10 & Sprint $20 \mathrm{~m}$ & 0,554 & $-0,055$ & $-0,103$ & 0,115 & 0,039 & 0,635 & 0,365 \\
\hline 11 & Running between stands & 0,407 & $-0,421$ & $-0,055$ & 0,747 & $-0,079$ & 0,911 & 0,089 \\
\hline 12 & Vertical jump & $-0,145$ & 0,404 & $-0,658$ & 0,117 & $-0,009$ & 0,630 & 0,370 \\
\hline 13 & Triple jump & $-0,061$ & 0,742 & $-0,251$ & $-0,055$ & $-0,145$ & 0,641 & 0,359 \\
\hline 14 & Throwing a thick ball & 0,293 & 0,524 & $-0,137$ & 0,044 & 0,509 & 0,640 & 0,360 \\
\hline 15 & Sit-ups & $-0,239$ & 0,653 & 0,329 & 0,337 & $-0,070$ & 0,710 & 0,290 \\
\hline 16 & "Shutter" running & 0,503 & $-0,473$ & 0,156 & $-0,228$ & $-0,317$ & 0,653 & 0,347 \\
\hline 17 & Eights with dribbling & $-0,327$ & 0,740 & 0,150 & 0,152 & 0,122 & 0,714 & 0,286 \\
\hline 18 & Dribbling stands & 0,485 & $-0,571$ & $-0,067$ & 0,507 & 0,310 & 0,919 & 0,081 \\
\hline 19 & Index for leading & 0,217 & $-0,356$ & $-0,032$ & $-0,032$ & 0,719 & 0,795 & 0,205 \\
\hline 20 & Movement with defense & 0,325 & $-0,688$ & $-0,235$ & $-0,088$ & 0,140 & 0,662 & 0,338 \\
\hline 21 & Shooting in movement-t & 0,358 & $-0,431$ & 0,597 & 0,055 & $-0,087$ & 0,680 & 0,320 \\
\hline 22 & Shooting in movement- coeff. & 0,275 & $-0,164$ & 0,478 & 0,323 & 0,009 & 0,435 & 0,565 \\
\hline 23 & Shooting from position $\%$ & $-0,231$ & 0,566 & 0,395 & 0,279 & 0,239 & 0,665 & 0,335 \\
\hline \multirow[t]{2}{*}{24} & Penalty hits \% successful & $-0,118$ & 0,376 & 0,469 & $-0,232$ & 0,153 & 0,452 & 0,548 \\
\hline & $\Sigma \mathbf{a}^{2}=\mathbf{7 0 , 7 7 \%}$ & 28,24 & 22,16 & 8,51 & 6,75 & 5,11 & & \\
\hline
\end{tabular}

Table 3. The average level of the players (specific of the game post)

\begin{tabular}{|c|c|c|c|c|}
\hline № & Indicators & Guards & Forwards & Centers \\
\hline 1 & Height & 182,52 & 191,39 & 201,67 \\
\hline 2 & Weight & 77,65 & 86,44 & 103,44 \\
\hline 4 & Horizontal Stretch & 183,40 & 193,10 & 202,86 \\
\hline 5 & Length of the upper limb & 82,13 & 84,27 & 92,83 \\
\hline 6 & Length of the lower limb & 109,50 & 115,45 & 120,83 \\
\hline 7 & Length of the palm & 20,06 & 20,92 & 22,08 \\
\hline 8 & Length of the foot & 27,25 & 28,39 & 29,97 \\
\hline 9 & Respiratory difference & 4,63 & 6,32 & 6,28 \\
\hline 10 & 20 m sprint & 3,01 & 3,12 & 3,22 \\
\hline 11 & Running between stands & 19,94 & 21,18 & 21,43 \\
\hline 12 & Vertical jump & 62,50 & 63,42 & 58,89 \\
\hline 13 & Triple jump & 6,71 & 6,88 & 6,85 \\
\hline 14 & Throwing a thick ball - backwards & 11,75 & 13,14 & 12,62 \\
\hline 15 & Sit-ups & 30,69 & 29,87 & 27,67 \\
\hline 16 & "Shutter” running & 62,89 & 65,23 & 68,67 \\
\hline 17 & Eights with dribbling & 59,12 & 54,68 & 50,22 \\
\hline 18 & Leading the ball between stands & 20,92 & 22,09 & 22,66 \\
\hline 19 & Index of leading the ball & 0,97 & 0,91 & 1,23 \\
\hline 20 & Moving in defense & 8,93 & 9,43 & 9,75 \\
\hline 21 & Shooting in movement-t & 6,39 & 32,87 & 33,61 \\
\hline 22 & Shooting with jump and feeder & 6,52 & 7,05 \\
\hline 23 & Penalty hits - \% successful & 58,49 & 50,00 \\
\hline 24 & & & 74,19 & 70,00 \\
\hline
\end{tabular}


The average level of each researched aggregate answers to $25 \mathrm{p}$. (Table 3 ). When there are better results than the average, the evaluations are higher than $25 \mathrm{p}$. and the opposite - when there are worse results, the values are lower than 25p.(adds.1-norm.tables) For the indicators where the lower values of the result answer to higher quality, the scales for evaluation are inverted. For us this is concerning the following indicators: $10 ; 11 ; 16 ; 18 ; 19 ; 20$; 21 and 22.

\section{Discussion and Conclusions}

According to the theory of the sport science [9] the adaptational process is a non-linear function of the physical loading, i.e. the dependency "dosis-effect" is developing by the so called logistic graph. This means that depending on the moment condition of the sign, for which the relevant indicator carries information, for the same quantity of training work, it will obtain different effect [11]. Therefore, the higher the level of development for a certain sign, i.e. the achievement is better, the more little growth we expect about it on a unit of training work. The results reflected that, the differences for the indicators 15,12 and 14 are a lot more evident. The maximal achievements of these indicators are over 2 times higher than the minimal. The differences in the achievements are naturally proving that the level of development of the signs of physical preparation is disadvantaged and they are reflecting on the values of the coefficient of the $\mathrm{V}$ variation. The values of the coefficient of the $\mathrm{V}$ variation for them are moving between $14,30 \%$ and $17,17 \%$, which from the point of view of the sport statistics is putting them in the zone of the relative stability. This gives us foundation to consider that the researched aggregate is relatively homogeneous regarding: the explosive power of the abdominal muscularity; the explosive power of the upper limbs and the shoulders during muscle efforts backwards and upwards; the explosive power of the lower limbs during vertical muscle efforts. The researched basketball players have done between 32 and 72 circle with the ball around the knees for the first test "Eigths". As we can see the difference between the biggest and the smallest achievement is evident. This is reflecting on the coefficient of the $\mathrm{V}$ variation. We can see that for this indicator $\mathrm{V}$ is $19,13 \%$. From the norms of the sport statistic this means that the researched aggregate is relatively 71 homogeneous regarding the ability of the boys included in it to handle the ball on one place. The lowest variable and therefore the most stable are the 18th and the 21st indicators where the values of the coefficient of variation are lower than $10 \%$ (respectively 8,47\% and 5,91\%). This gives us foundation to think that the whole researched aggregate is homogeneous regarding the rapidity of movement on the playground with leading the ball which is decisive factor during the performance of speed shooting in movement. The highest variable and therefore unstable is indicator 19 . The value of the coefficient of variation there is almost $95 \%$. This gives us foundation to consider that the researched aggregate is non-homogeneous regarding the ability of the basketball players from the university teams to perform master leading off the ball (table 1).

The general review on the factor structure shows that for the researched Turkish basketball players, the signs for the physical development and the special physical preparation are defining. They are building the first four factors of the observed occurrence and have positive influence on the specific abilities of the competitors. Only the last one (5-th) factor is linked only with the specific ability to lead the ball with high speed.

The analysis of the results and the summaries that are made in the text allow us to form the following conclusions:

1. The evaluation of the body mass is in the zone of the norm, in general.

2. The individual features in the development of the observed signs are reflecting on the homogeneity of the researched aggregate with high guarantee probability, we can say that the observed aggregates are homogeneous regarding the signs of the physical development, the rapidity of movement on the ground with leading the ball and the speed shooting in movement; non-homogeneity is observed regarding the level of development of the functional capacity of the chest and the ability of the basketball players from the universities to lead the ball with high speed; the rest of the researched indicators are relatively stable, and the researched aggregate - relatively homogeneous regarding the signs, which these indicators carry information about.

3. The factor structure of the physical development and the specific workability of the students from the Turkish basketball teams is based on 5 basic factors, which explain high percent $(70,77 \%)$ of the starting dispersion of the researched occurrence. The first and the most_important factor defines the significance of morphological signs which influence positively on the rapidity movement and the speed endurance of the basketball players (table 2). 


\section{Appendix}

\section{Normative Tables}

Centers

\begin{tabular}{|c|c|c|c|c|c|c|c|c|c|c|c|c|c|c|c|c|c|c|c|c|c|c|c|}
\hline \multirow{2}{*}{ Points } & \multicolumn{23}{|c|}{ INDICATORS } \\
\hline & 1 & 2 & 4 & 5 & 6 & 7 & 8 & 9 & 10 & 11 & 12 & 13 & 14 & 15 & 16 & 17 & 18 & 19 & 20 & 21 & 22 & 23 & 24 \\
\hline 50 & 208,14 & 125,29 & 213,86 & 101,58 & 128,08 & 25,51 & 32,92 & 13,78 & 2,75 & 18,43 & 78,89 & 8,35 & 16,45 & 41,87 & 61,17 & 71,22 & 18,66 & 0,23 & 7,25 & 29,11 & 4,55 & 77,50 & 97,50 \\
\hline 49 & 207,88 & 124,42 & 213,42 & 101,23 & 127,79 & 25,37 & 32,80 & 13,48 & 2,76 & 18,55 & 78,09 & 8,29 & 16,29 & 41,30 & 61,47 & 70,38 & 18,82 & 0,27 & 7,35 & 29,29 & 4,65 & 76,40 & 96,40 \\
\hline 48 & 207,62 & 123,55 & 212,98 & 100,88 & 127,50 & 25,23 & 32,69 & 13,18 & 2,78 & 18,67 & 77,29 & 8,23 & 16,14 & 40,73 & 61,77 & 69,54 & 18,98 & 0,31 & 7,45 & 29,47 & 4,75 & 75,30 & 95,30 \\
\hline 47 & 207,36 & 122,67 & 212,54 & 100,53 & 127,21 & 25,10 & 32,57 & 12,88 & 2,80 & 18,79 & 76,49 & 8,17 & 15,99 & 40,16 & 62,07 & 68,70 & 19,14 & 0,35 & 7,55 & 29,65 & 4,85 & 74,20 & 94,20 \\
\hline 46 & 207,11 & 121,80 & 212,10 & 100,18 & 126,92 & 24,96 & 32,45 & 12,58 & 2,82 & 18,91 & 75,69 & 8,11 & 15,83 & 39,59 & 62,37 & 67,86 & 19,30 & 0,39 & 7,65 & 29,83 & 4,95 & 73,10 & 93,10 \\
\hline 45 & 206,85 & 120,92 & 211,66 & 99,83 & 126,63 & 24,82 & 32,33 & 12,28 & 2,84 & 19,03 & 74,89 & 8,05 & 15,68 & 39,03 & 62,67 & 67,02 & 19,46 & 0,43 & 7,75 & 30,01 & 5,05 & 72,00 & 92,00 \\
\hline 44 & 206,59 & 120,05 & 211,22 & 99,48 & 126,34 & 24,69 & 32,21 & 11,98 & 2,86 & 19,15 & 74,09 & 7,99 & 15,53 & 38,46 & 62,97 & 66,18 & 19,62 & 0,47 & 7,85 & 30,19 & 5,15 & 70,90 & 90,90 \\
\hline 43 & 206,33 & 119,18 & 210,78 & 99,13 & 126,05 & 24,55 & 32,10 & 11,68 & 2,88 & 19,27 & 73,29 & 7,93 & 15,37 & 37,89 & 63,27 & 65,34 & 19,78 & 0,51 & 7,95 & 30,37 & 5,25 & 69,80 & 89,80 \\
\hline 42 & 206,07 & 118,30 & 210,34 & 98,78 & 125,76 & 24,41 & 31,98 & 11,38 & 2,90 & 19,39 & 72,49 & 7,87 & 15,22 & 37,32 & 63,57 & 64,50 & 19,94 & 0,55 & 8,05 & 30,55 & 5,35 & 68,70 & 88,70 \\
\hline 41 & 205,81 & 117,43 & 209,90 & 98,43 & 125,47 & 24,28 & 31,86 & 11,08 & 2,92 & 19,51 & 71,69 & 7,81 & 15,07 & 36,75 & 63,87 & 63,66 & 20,10 & 0,59 & 8,15 & 30,73 & 5,45 & 67,60 & 87,60 \\
\hline 40 & 205,55 & 116,55 & 209,46 & 98,08 & 125,18 & 24,14 & 31,74 & 10,78 & 2,94 & 19,63 & 70,89 & 7,75 & 14,92 & 36,19 & 64,17 & 62,82 & 20,26 & 0,63 & 8,25 & 30,91 & 5,55 & 66,50 & 86,50 \\
\hline 39 & 205,29 & 115,68 & 209,02 & 97,73 & 124,89 & 24,00 & 31,62 & 10,48 & 2,95 & 19,75 & 70,09 & 7,69 & 14,76 & 35,62 & 64,47 & 61,98 & 20,42 & 0,67 & 8,35 & 31,09 & 5,65 & 65,40 & 85,40 \\
\hline 38 & 205,03 & 114,81 & 208,58 & 97,38 & 124,60 & 23,86 & 31,51 & 10,18 & 2,97 & 19,87 & 69,29 & 7,63 & 14,61 & 35,05 & 64,77 & 61,14 & 20,58 & 0,71 & 8,45 & 31,27 & 5,75 & 64,30 & 84,30 \\
\hline 37 & 204,77 & 113,93 & 208,14 & 97,03 & 124,31 & 23,73 & 31,39 & 9,88 & 2,99 & 19,99 & 68,49 & 7,57 & 14,46 & 34,48 & 65,07 & 60,30 & 20,74 & 0,75 & 8,55 & 31,45 & 5,85 & 63,20 & 83,20 \\
\hline 36 & 204,52 & 113,06 & 207,70 & 96,68 & 124,02 & 23,59 & 31,27 & 9,58 & 3,01 & 20,11 & 67,69 & 7,51 & 14,30 & 33,91 & 65,37 & 59,46 & 20,90 & 0,79 & 8,65 & 31,63 & 5,95 & 62,10 & 82,10 \\
\hline 35 & 204,26 & 112,18 & 207,26 & 96,33 & 123,73 & 23,45 & 31,15 & 9,28 & 3,03 & 20,23 & 66,89 & 7,45 & 14,15 & 33,35 & 65,67 & 58,62 & 21,06 & 0,83 & 8,75 & 31,81 & 6,05 & 61,00 & 81,00 \\
\hline 34 & 204,00 & 111,31 & 206,82 & 95,98 & 123,44 & 23,32 & 31,03 & 8,98 & 3,05 & 20,35 & 66,09 & 7,39 & 14,00 & 32,78 & 65,97 & 57,78 & 21,22 & 0,87 & 8,85 & 31,99 & 6,15 & 59,90 & 79,90 \\
\hline 33 & 203,74 & 110,44 & 206,38 & 95,63 & 123,15 & 23,18 & 30,92 & 8,68 & 3,07 & 20,47 & 65,29 & 7,33 & 13,84 & 32,21 & 66,27 & 56,94 & 21,38 & 0,91 & 8,95 & 32,17 & 6,25 & 58,80 & 78,80 \\
\hline 32 & 203,48 & 109,56 & 205,94 & 95,28 & 122,86 & 23,04 & 30,80 & 8,38 & 3,09 & 20,59 & 64,49 & 7,27 & 13,69 & 31,64 & 66,57 & 56,10 & 21,54 & 0,95 & 9,05 & 32,35 & 6,35 & 57,70 & 77,70 \\
\hline 31 & 203,22 & 108,69 & 205,50 & 94,93 & 122,57 & 22,91 & 30,68 & 8,08 & 3,11 & 20,71 & 63,69 & 7,21 & 13,54 & 31,07 & 66,87 & 55,26 & 21,70 & 0,99 & 9,15 & 32,53 & 6,45 & 56,60 & 76,60 \\
\hline 30 & 202,96 & 107,81 & 205,06 & 94,58 & 122,28 & 22,77 & 30,56 & 7,78 & 3,13 & 20,83 & 62,89 & 7,15 & 13,39 & 30,51 & 67,17 & 54,42 & 21,86 & 1,03 & 9,25 & 32,71 & 6,55 & 55,50 & 75,50 \\
\hline 29 & 202,70 & 106,94 & 204,62 & 94,23 & 121,99 & 22,63 & 30,44 & 7,48 & 3,14 & 20,95 & 62,09 & 7,09 & 13,23 & 29,94 & 67,47 & 53,58 & 22,02 & 1,07 & 9,35 & 32,89 & 6,65 & 54,40 & 74,40 \\
\hline
\end{tabular}




\begin{tabular}{|c|c|c|c|c|c|c|c|c|c|c|c|c|c|c|c|c|c|c|c|c|c|c|c|}
\hline 28 & 2,44 & 106,07 & 204,18 & 93,88 & 121,70 & 22,49 & 30,33 & 7,18 & 3,16 & 21,07 & 61,29 & 7,03 & 13,08 & 29,37 & 67,77 & 52,74 & 22,18 & 1,11 & 9,45 & 33,07 & 6,75 & 53,30 & 73,30 \\
\hline 27 & 202,18 & 105,19 & 203,74 & 93,53 & 121,41 & 22,36 & 30,21 & 6,88 & 3,18 & 21,19 & 60,49 & 6,97 & 12,93 & 28,80 & 68,07 & 51,90 & 22,34 & 1,15 & 9,55 & 33,25 & 6,85 & 52,20 & 72,20 \\
\hline 26 & 201,93 & 104,32 & 203,30 & 93,18 & 121,12 & 22,22 & 30,09 & 6,58 & 3,20 & 21,31 & 59,69 & 6,91 & 12,77 & 28,23 & 68,37 & 51,06 & 22,50 & 1,19 & 9,65 & 33,43 & 6,95 & 51,10 & 71,10 \\
\hline$\underline{25}$ & 01,67 & 103,44 & 202,86 & $\underline{92,83}$ & $\underline{120,83}$ & $\underline{22,08}$ & 29,97 & $\underline{6,28}$ & $\underline{3,22}$ & 21,43 & $\underline{58,89}$ & 6,85 & 12,62 & 27,67 & $\underline{68,67}$ & $\underline{50,22}$ & $\underline{22,66}$ & $\underline{1,23}$ & 9,75 & $\underline{33,61}$ & 7,05 & 50,00 & $\underline{70,00}$ \\
\hline 24 & 01,41 & 102,47 & 2,40 & 92,36 & 120,43 & 21,98 & 29,88 & 6,08 & 3,24 & 21,56 & 58,24 & 6,80 & 12,49 & 27,17 & 69,12 & 49,72 & 22,82 & 1,27 & 9,85 & 33,83 & 7,24 & 48,90 & 68,90 \\
\hline 23 & 201,15 & 101,50 & 201,93 & 91,89 & 120,03 & 21,88 & 29,79 & 5,88 & 3,25 & 21,69 & 57,59 & 6,76 & 12,35 & 26,67 & 69,57 & 49,22 & 22,98 & 1,31 & 9,95 & 34,05 & 7,43 & 47,80 & 67,80 \\
\hline 22 & 200,89 & 100,53 & 201,46 & 91,42 & 119,63 & 21,78 & 29,70 & 5,68 & 3,27 & 21,82 & 56,94 & 6,71 & 12,22 & 26,17 & 70,03 & 48,72 & 23,14 & 1,35 & 10,05 & 34,27 & 7,62 & 46,70 & 66,70 \\
\hline 19 & 200,11 & 97,62 & 200,07 & 90,01 & 118,43 & 21,48 & 29,43 & 5,08 & 3,31 & 22,21 & 54,99 & 6,58 & 11,82 & 24,67 & 71,39 & 47,22 & 23,62 & 1,47 & 10,35 & 34,93 & 8,19 & 43,40 & 63,40 \\
\hline 18 & 199,85 & 96,65 & 199,60 & 89,54 & 118,03 & 21,38 & 29,34 & 4,88 & 3,33 & 22,34 & 54,34 & 6,53 & 11,69 & 24,17 & 71,84 & 46,72 & 23,78 & 1,51 & 10,45 & 35,15 & 8,38 & 42,30 & 62,30 \\
\hline 17 & 199,59 & 95,68 & 199,13 & 89,07 & 117,63 & 21,28 & 29,25 & 4,68 & 3,34 & 22,47 & 53,69 & 6,49 & 11,56 & 23,67 & 72,30 & 46,22 & 23,94 & 1,55 & 10,55 & 35,37 & 8,57 & 41,20 & 61,20 \\
\hline 16 & 199,34 & 94,71 & 198,67 & 88,59 & 117,23 & 21,18 & 29,16 & 4,48 & 3,36 & 22,60 & 53,04 & 6,44 & 11,42 & 23,17 & 72,75 & 45,72 & 24,10 & 1,59 & 10,65 & 35,59 & 8,76 & 40,10 & 60,10 \\
\hline 15 & 199,08 & 93,74 & 198,20 & 88,12 & 116,83 & 21,08 & 29,07 & 4,28 & 3,37 & 22,73 & 52,39 & 6,40 & 11,29 & 22,67 & 73,21 & 45,22 & 24,26 & 1,63 & 10,75 & 35,81 & 8,95 & 39,00 & 59,00 \\
\hline 11 & 198,04 & 89,86 & 196,34 & 86,24 & 115,23 & 20,68 & 28,71 & 3,48 & 3,43 & 23,25 & 49,79 & 6,22 & 10,76 & 20,67 & 75,02 & 43,22 & 24,90 & 1,79 & 11,15 & 36,69 & 9,71 & 34,60 & 54,60 \\
\hline 10 & 197,78 & 88,89 & 195,87 & 85,77 & 114,83 & 20,58 & 28,62 & 3,28 & 3,45 & 23,38 & 49,14 & 6,17 & 10,63 & 20,17 & 75,48 & 42,72 & 25,06 & 1,83 & 11,25 & 36,91 & 9,90 & 33,50 & 53,50 \\
\hline 9 & 197,52 & 87,92 & 195,41 & 85,30 & 114,43 & 20,48 & 28,53 & 3,08 & 3,46 & 23,51 & 48,49 & 6,13 & 10,49 & 19,67 & 75,93 & 42,22 & 25,22 & 1,87 & 11,35 & 37,13 & 10,09 & 32,40 & 52,40 \\
\hline 8 & 197,26 & 86,95 & 194,94 & 84,83 & 114,03 & 20,38 & 28,44 & 2,88 & 3,48 & 23,64 & 47,84 & 6,08 & 10,36 & 19,17 & 76,38 & 41,72 & 25,38 & 1,91 & 11,45 & 37,35 & 10,28 & 31,30 & 51,30 \\
\hline 7 & \begin{tabular}{|l}
197,00 \\
\end{tabular} & 85,98 & 194,47 & 84,36 & 113,63 & 20,28 & 28,35 & $\begin{array}{r}2,68 \\
\end{array}$ & 3,49 & 23,77 & 47,19 & 6,04 & 10,23 & 18,67 & 76,84 & 41,22 & 25,54 & $\begin{array}{r}1,95 \\
\end{array}$ & 11,55 & 37,57 & 10,47 & 30,20 & 50,20 \\
\hline 6 & 196,75 & 85,01 & 194,01 & 83,88 & 113,23 & 20,18 & 28,26 & 2,48 & 3,51 & 23,90 & 46,54 & 5,99 & 10,09 & 18,17 & 77,29 & 40,72 & 25,70 & 1,99 & 11,65 & 37,79 & 10,66 & 29,10 & 49,10 \\
\hline 5 & 196,49 & 84,04 & 193,54 & 83,41 & 112,83 & 20,08 & 28,17 & 2,28 & 3,52 & 24,03 & 45,89 & 5,95 & 9,96 & 17,67 & 77,75 & 40,22 & 25,86 & 2,03 & 11,75 & 38,01 & 10,85 & 28,00 & 48,00 \\
\hline 4 & 196,23 & 83,07 & 193,08 & 82,94 & 112,43 & 19,98 & 28,08 & 2,08 & 3,54 & 24,16 & 45,24 & 5,90 & 9,83 & 17,17 & 78,20 & 39,72 & 26,02 & 2,07 & 11,85 & 38,23 & 11,04 & 26,90 & 46,90 \\
\hline 3 & 195,97 & 82,10 & 192,61 & 82,47 & 112,03 & 19,88 & 27,99 & 1,88 & 3,55 & 24,29 & 44,59 & 5,86 & 9,69 & 16,67 & 78,65 & 39,22 & 26,18 & 2,11 & 11,95 & 38,45 & 11,23 & 25,80 & 45,80 \\
\hline 2 & 195,71 & 81,13 & 192,14 & 82,00 & 111,63 & 19,78 & 27,90 & 1,68 & 3,57 & \begin{tabular}{|l}
24,42 \\
\end{tabular} & 43,94 & 5,81 & & 16,17 & 79,11 & $\begin{array}{r}38,72 \\
\end{array}$ & 26,34 & 2,15 & 12,05 & 38,67 & 11,42 & 24,70 & 44,70 \\
\hline
\end{tabular}


Forwards

\begin{tabular}{|c|c|c|c|c|c|c|c|c|c|c|c|c|c|c|c|c|c|c|c|c|c|c|c|}
\hline \multirow{2}{*}{ Points } & \multicolumn{23}{|c|}{ INDICATORS } \\
\hline & 1 & 2 & 4 & 5 & 6 & 7 & 8 & 9 & 10 & 11 & 12 & 13 & 14 & 15 & 16 & 17 & 18 & 19 & 20 & 21 & 22 & 23 & 24 \\
\hline 50 & 206,39 & 105,94 & 205,85 & 97,27 & 129,20 & 23,99 & 31,39 & 13,82 & 2,72 & 17,68 & 79,67 & 8,38 & 17,14 & 41,10 & 57,73 & 75,43 & 18,59 & 0,16 & 7,18 & 29,73 & 4,52 & 80,99 & 99,42 \\
\hline 49 & 205,79 & 105,16 & 205,34 & 96,75 & 128,65 & 23,87 & 31,27 & 13,52 & 2,74 & 17,82 & 79,02 & 8,32 & 16,98 & 40,65 & 58,03 & 74,60 & 18,73 & 0,19 & 7,27 & 29,83 & 4,60 & 80,09 & 98,41 \\
\hline 48 & 205,19 & 104,38 & 204,83 & 96,23 & 128,10 & 23,75 & 31,15 & 13,22 & 2,75 & 17,96 & 78,37 & 8,26 & 16,82 & 40,20 & 58,33 & 73,77 & 18,87 & 0,22 & 7,36 & 29,93 & 4,68 & 79,19 & 97,40 \\
\hline 47 & 204,59 & 103,60 & 204,32 & 95,71 & 127,55 & 23,63 & 31,03 & 12,92 & 2,77 & 18,10 & 77,72 & 8,20 & 16,66 & 39,75 & 58,63 & 72,94 & 19,01 & 0,25 & 7,45 & 30,03 & 4,76 & 78,29 & 96,39 \\
\hline 46 & 203,99 & 102,82 & 203,81 & 95,19 & 127,00 & 23,50 & 30,91 & 12,62 & 2,79 & 18,24 & 77,07 & 8,14 & 16,50 & 39,30 & 58,93 & 72,11 & 19,15 & 0,28 & 7,54 & 30,13 & 4,84 & 77,39 & 95,38 \\
\hline 43 & 202,19 & 100,48 & 202,28 & 93,63 & 125,35 & 23,13 & 30,55 & 11,72 & 2,83 & 18,66 & 75,12 & 7,96 & 16,02 & 37,95 & 59,83 & 69,62 & 19,57 & 0,37 & 7,81 & 30,43 & 5,08 & 74,69 & 92,36 \\
\hline 42 & 201,59 & 99,70 & 201,77 & 93,11 & 124,80 & 23,01 & 30,43 & 11,42 & 2,85 & 18,80 & 74,47 & 7,90 & 15,86 & 37,50 & 60,13 & 68,79 & 19,71 & 0,40 & 7,90 & 30,53 & 5,16 & 73,79 & 91,35 \\
\hline 41 & 200,99 & 98,92 & 201,26 & 92,59 & 124,25 & 22,89 & 30,31 & 11,12 & 2,87 & 18,94 & 73,82 & 7,84 & 15,70 & 37,05 & 60,43 & 67,96 & 19,85 & 0,43 & 7,99 & 30,63 & 5,24 & 72,89 & 90,34 \\
\hline 40 & 200,39 & 98,14 & 200,75 & 92,07 & 123,70 & 22,76 & 30,19 & 10,82 & 2,88 & 19,08 & 73,17 & 7,78 & 15,54 & 36,61 & 60,73 & 67,13 & 19,99 & 0,46 & 8,08 & 30,73 & 5,32 & 71,99 & 89,33 \\
\hline 39 & 199,79 & 97,36 & 200,24 & 91,55 & 123,15 & 22,64 & \begin{tabular}{|l|l}
30,07 \\
\end{tabular} & 10,52 & 2,90 & 19,22 & 72,52 & 7,72 & 15,38 & 36,16 & 61,03 & 66,30 & 20,13 & 0,49 & 8,17 & 30,83 & 5,40 & 71,09 & 88,32 \\
\hline 35 & 197,39 & 94,24 & 198,20 & 89,47 & 120,95 & 22,15 & $\mid 29,59$ & 9,32 & 2,96 & 19,78 & 69,92 & 7,48 & 14,74 & 34,36 & 62,23 & 62,98 & 20,69 & 0,61 & 8,53 & 31,23 & 5,72 & 67,49 & 84,28 \\
\hline 34 & 196,79 & 93,46 & 197,69 & 88,95 & 120,40 & 22,03 & $\mid 29,47$ & 9,02 & 2,98 & 19,92 & 69,27 & 7,42 & 14,58 & 33,91 & 62,53 & 62,15 & 20,83 & 0,64 & 8,62 & 31,33 & 5,80 & 66,59 & 83,27 \\
\hline 33 & 196,19 & 92,68 & 197,18 & 88,43 & 119,85 & 21,90 & 29,35 & 8,72 & 2,99 & 20,06 & 68,62 & 7,36 & 14,42 & 33,46 & 62,83 & $\mid 61,32$ & 20,97 & 0,67 & 8,71 & 31,43 & 5,88 & 65,69 & 82,27 \\
\hline 32 & 195,59 & 91,90 & 196,67 & 87,91 & 119,30 & 21,78 & 29,23 & 8,42 & 3,01 & 20,20 & $\mid 67,97$ & 7,30 & 14,26 & 33,01 & 63,13 & 60,49 & 21,11 & 0,70 & 8,80 & 31,53 & 5,96 & 64,79 & 81,26 \\
\hline 31 & 194,99 & 91,12 & 196,16 & 87,39 & 118,75 & 21,66 & 29,11 & 8,12 & 3,03 & 20,34 & 67,32 & 7,24 & 14,10 & 32,56 & 63,43 & 59,66 & 21,25 & 0,73 & 8,89 & 31,63 & 6,04 & 63,89 & 80,25 \\
\hline 30 & 194,39 & 90,34 & 195,65 & 86,87 & 118,20 & 21,53 & 28,99 & 7,82 & 3,04 & 20,48 & 66,67 & 7,18 & 13,94 & 32,12 & 63,73 & 58,83 & 21,39 & 0,76 & 8,98 & 31,73 & 6,12 & 62,99 & 79,24 \\
\hline 29 & 193,79 & 89,56 & 195,14 & 86,35 & 117,65 & 21,41 & $\mid 28,87$ & 7,52 & 3,06 & 20,62 & 66,02 & 7,12 & 13,78 & 31,67 & 64,03 & 58,00 & 21,53 & 0,79 & 9,07 & 31,83 & 6,20 & 62,09 & 78,23 \\
\hline 28 & 193,19 & 88,78 & 194,63 & 85,83 & 117,10 & 21,29 & 28,75 & 7,22 & 3,07 & 20,76 & 65,37 & 7,06 & 13,62 & 31,22 & 64,33 & 57,17 & 21,67 & 0,82 & 9,16 & 31,93 & 6,28 & 61,19 & 77,22 \\
\hline 27 & 192,59 & 88,00 & 194,12 & 85,31 & 116,55 & 21,17 & 28,63 & 6,92 & 3,09 & 20,90 & 64,72 & 7,00 & 13,46 & 30,77 & 64,63 & 56,34 & 21,81 & 0,85 & 9,25 & 32,03 & 6,36 & 60,29 & 76,21 \\
\hline 26 & 191,99 & 87,22 & 193,61 & 84,79 & 116,00 & 21,04 & 28,51 & 6,62 & 3,11 & 21,04 & 64,07 & 6,94 & 13,30 & 30,32 & 64,93 & 55,51 & 21,95 & 0,88 & 9,34 & 32,13 & 6,44 & 59,39 & 75,20 \\
\hline
\end{tabular}




\begin{tabular}{|c|c|c|c|c|c|c|c|c|c|c|c|c|c|c|c|c|c|c|c|c|c|c|c|}
\hline$\underline{25}$ & $\underline{191,39}$ & $\underline{86,44}$ & $\underline{193,10}$ & $\underline{84,27}$ & $\underline{115,45}$ & $\underline{20,92}$ & $\underline{28,39}$ & $\underline{6,32}$ & $\underline{3,12}$ & $\underline{21,18}$ & $\underline{63,42}$ & $\underline{6,88}$ & $\underline{13,14}$ & $\underline{29,87}$ & $\underline{65,23}$ & $\underline{54,68}$ & $\underline{22,09}$ & $\underline{0,91}$ & $\underline{9,43}$ & $\underline{32,23}$ & $\underline{6,52}$ & $\underline{58,49}$ & $\underline{74,19}$ \\
\hline 24 & 190,79 & 85,66 & 192,55 & 83,65 & 114,80 & 20,82 & 28,27 & 6,12 & 3,14 & 21,32 & 62,57 & 6,83 & 12,98 & 29,53 & 65,53 & 53,85 & 22,23 & 0,96 & 9,52 & 32,40 & 6,67 & 57,59 & 73,18 \\
\hline 23 & 190,19 & 84,88 & 92,00 & 83,03 & 114,15 & 20,72 & 28,15 & 5,92 & 3,15 & 21,46 & 61,72 & 6,78 & 12,82 & 29,19 & 65,83 & 53,02 & 22,37 & 1,01 & 9,61 & 32,57 & 6,82 & 56,69 & 72,18 \\
\hline 22 & 189,59 & 84,10 & 191,45 & 82,41 & 113,50 & 20,62 & 28,03 & 5,72 & 3,17 & 21,60 & 60,87 & 6,73 & 12,66 & 28,85 & 66,13 & 52,19 & 22,51 & 1,06 & 9,70 & 32,74 & 6,97 & 55,79 & 71,17 \\
\hline 21 & 188,99 & 83,32 & 190,90 & 81,79 & 112,85 & 20,52 & 27,91 & 5,52 & 3,19 & 21,74 & 60,02 & 6,68 & 12,50 & 28,51 & 66,43 & 51,36 & 22,65 & 1,11 & 9,79 & 32,91 & 7,12 & 54,89 & 70,16 \\
\hline 20 & 188,39 & 82,54 & 190,35 & 81,17 & 112,20 & 20,42 & 27,79 & 5,32 & 3,20 & 21,88 & 59,17 & 6,63 & 12,34 & 28,17 & 66,73 & 50,53 & 22,79 & 1,16 & 9,88 & 33,08 & 7,27 & 53,99 & 69,15 \\
\hline 19 & 187,79 & 81,76 & 189,80 & 80,55 & 111,55 & 20,32 & 27,67 & 5,12 & 3,22 & 22,02 & 58,32 & 6,58 & 12,18 & 27,83 & 67,03 & 49,70 & 22,93 & 1,21 & 9,97 & 33,25 & 7,42 & 53,09 & 68,14 \\
\hline 18 & 187,19 & 80,98 & 189,25 & 79,93 & 110,90 & 20,22 & 27,55 & 4,92 & 3,23 & 22,16 & 57,47 & 6,53 & 12,02 & 27,49 & 67,33 & 48,87 & 23,07 & 1,26 & 10,06 & 33,42 & 7,57 & 52,19 & 67,13 \\
\hline 17 & 186,59 & 80,20 & 188,70 & 79,31 & 110,25 & 20,12 & 27,43 & 4,72 & 3,25 & 22,30 & 56,62 & 6,48 & 11,86 & 27,15 & 67,63 & 48,04 & 23,21 & 1,31 & 10,15 & 33,59 & 7,72 & 51,29 & 66,12 \\
\hline 16 & 185,99 & 79,42 & 188,15 & 78,69 & 109,60 & 20,02 & 27,31 & 4,52 & 3,27 & 22,44 & 55,77 & 6,43 & 11,70 & 26,81 & 67,93 & 47,21 & 23,35 & 1,36 & 10,24 & 33,76 & 7,87 & 50,39 & 65,11 \\
\hline 15 & 185,39 & 78,64 & 187,60 & 78,07 & 108,95 & 19,92 & 27,19 & 4,32 & 3,28 & 22,58 & 54,92 & 6,38 & 11,54 & 26,47 & 68,23 & 46,38 & 23,49 & 1,41 & 10,33 & 33,93 & 8,02 & 49,49 & 64,10 \\
\hline 14 & 184,79 & 77,86 & 187,05 & 77,45 & 108,30 & 19,82 & 27,07 & 4,12 & 3,30 & 22,72 & 54,07 & 6,33 & 11,38 & 26,13 & 68,53 & 45,55 & 23,63 & 1,46 & 10,42 & 34,10 & 8,17 & 48,59 & 63,09 \\
\hline 13 & 184,19 & 77,08 & 186,50 & 76,83 & 107,65 & 19,72 & 26,95 & 3,92 & 3,31 & 22,86 & 53,22 & 6,28 & 11,22 & 25,79 & 68,83 & 44,72 & 23,77 & 1,51 & 10,51 & 34,27 & 8,32 & 47,69 & 62,09 \\
\hline 12 & 183,59 & 76,30 & 185,95 & 76,21 & 107,00 & 19,62 & 26,83 & 3,72 & 3,33 & 23,00 & 52,37 & 6,23 & 11,06 & 25,45 & 69,13 & 43,89 & 23,91 & 1,56 & 10,60 & 34,44 & 8,47 & 46,79 & 61,08 \\
\hline 11 & 182,99 & 75,52 & 185,40 & 75,59 & 106,35 & 19,52 & 26,71 & 3,52 & 3,35 & 23,14 & 51,52 & 6,18 & 10,90 & 25,11 & 69,43 & 43,06 & 24,05 & 1,61 & 10,69 & 34,61 & 8,62 & 45,89 & 60,07 \\
\hline 10 & 182,39 & 74,74 & 184,85 & 74,97 & 105,70 & 19,42 & 26,59 & 3,32 & 3,36 & 23,28 & 50,67 & 6,13 & 10,74 & 24,77 & 69,73 & 42,23 & 24,19 & 1,66 & 10,78 & 34,78 & 8,77 & 44,99 & 59,06 \\
\hline 9 & 181,79 & 73,96 & 184,30 & 74,35 & 105,05 & 19,32 & 26,47 & 3,12 & 3,38 & 23,42 & 49,82 & 6,08 & 10,58 & 24,43 & 70,03 & 41,40 & 24,33 & 1,71 & 10,87 & 34,95 & 8,92 & 44,09 & 58,05 \\
\hline 8 & 181,19 & 73,18 & 183,75 & 73,73 & 104,40 & 19,22 & 26,35 & 2,92 & 3,39 & 23,56 & 48,97 & 6,03 & 10,42 & 24,09 & 70,33 & 40,57 & 24,47 & 1,76 & 10,96 & 35,12 & 9,07 & 43,19 & 57,04 \\
\hline 7 & 180,59 & 72,40 & 183,20 & 73,11 & 103,75 & 19,12 & 26,23 & 2,72 & 3,41 & 23,70 & 48,12 & 5,98 & 10,26 & 23,75 & 70,63 & 39,74 & 24,61 & 1,81 & 11,05 & 35,29 & 9,22 & 42,29 & 56,03 \\
\hline 6 & 179,99 & 71,62 & 182,65 & 72,49 & 103,10 & 19,02 & 26,11 & 2,52 & 3,43 & 23,84 & 47,27 & 5,93 & 10,10 & 23,41 & 70,93 & 38,91 & 24,75 & 1,86 & 11,14 & 35,46 & 9,37 & 41,39 & 55,02 \\
\hline 5 & 179,39 & 70,84 & 182,10 & 71,87 & 102,45 & 18,92 & 25,99 & 2,32 & 3,44 & 23,98 & 46,42 & 5,88 & 9,94 & 23,07 & 71,23 & 38,08 & 24,89 & 1,91 & 11,23 & 35,63 & 9,52 & 40,49 & 54,01 \\
\hline 4 & 178,79 & 70,06 & 181,55 & 71,25 & 101,80 & 18,82 & 25,87 & 2,12 & 3,46 & 24,12 & 45,57 & 5,83 & 9,78 & 22,73 & 71,53 & 37,25 & 25,03 & 1,96 & 11,32 & 35,80 & 9,67 & 39,59 & 53,00 \\
\hline 3 & 178,19 & 69,28 & 181,00 & 70,63 & 101,15 & 18,72 & 25,75 & 1,92 & 3,47 & 24,26 & 44,72 & 5,78 & 9,62 & 22,39 & 71,83 & 36,42 & 25,17 & 2,01 & 11,41 & 35,97 & 9,82 & 38,69 & 52,00 \\
\hline 2 & 177,59 & 68,50 & 180,45 & 70,01 & 100,50 & 18,62 & 25,63 & 1,72 & 3,49 & 24,40 & 43,87 & 5,73 & 9,46 & 22,05 & 72,13 & 35,59 & 25,31 & 2,06 & 11,50 & 36,14 & 9,97 & 37,79 & 50,99 \\
\hline 1 & 176,99 & 67,72 & 179,90 & 69,39 & 99,85 & 18,52 & 25,51 & 1,52 & 3,51 & 24,54 & 43,02 & 5,68 & 9,30 & 21,71 & 72,43 & 34,76 & 25,45 & 2,11 & 11,59 & 36,31 & 10,12 & 36,89 & 49,98 \\
\hline
\end{tabular}


Guards

\begin{tabular}{|c|c|c|c|c|c|c|c|c|c|c|c|c|c|c|c|c|c|c|c|c|c|c|c|}
\hline \multirow{2}{*}{ Points } & \multicolumn{23}{|c|}{ INDICATORS } \\
\hline & 1 & 2 & 4 & 5 & 6 & 7 & 8 & 9 & 10 & 11 & 12 & 13 & 14 & 15 & 16 & 17 & 18 & 19 & 20 & 21 & 22 & 23 & 24 \\
\hline 50 & 193,77 & 97,65 & 194,65 & 94,63 & 119,50 & 21,31 & 29,85 & 8,63 & 2,61 & 17,82 & 76,25 & 7,96 & 16,12 & 39,44 & 57,39 & 74,12 & 17,87 & 0,10 & 6,93 & 28,29 & 4,39 & 80,77 & 92,37 \\
\hline 49 & 193,32 & 96,85 & 194,20 & 94,13 & 119,10 & 21,26 & 29,75 & 8,47 & 2,63 & 17,90 & 75,70 & 7,91 & 15,95 & 39,09 & 57,61 & 73,52 & 17,99 & 0,13 & 7,01 & 28,43 & 4,47 & 79,97 & 91,56 \\
\hline 48 & 192,87 & 96,05 & 193,75 & 93,63 & 118,70 & 21,21 & 29,64 & 8,31 & 2,64 & 17,99 & 75,15 & 7,86 & 15,77 & 38,74 & 57,83 & 72,92 & 18,11 & 0,17 & 7,09 & 28,58 & 4,55 & 79,17 & 90,75 \\
\hline 47 & 192,42 & 95,25 & 193,30 & 93,13 & 118,30 & 21,16 & 29,54 & 8,15 & 2,66 & 18,07 & 74,60 & 7,81 & 15,60 & 38,39 & 58,05 & 72,32 & 18,23 & 0,20 & 7,17 & 28,72 & 4,63 & 78,37 & 89,94 \\
\hline 46 & 191,97 & 94,45 & 192,85 & 92,63 & 117,90 & 21,11 & 29,43 & 7,99 & 2,67 & 18,16 & 74,05 & 7,76 & 15,42 & 38,04 & 58,27 & 71,72 & 18,35 & 0,24 & 7,25 & 28,86 & 4,71 & 77,57 & 89,13 \\
\hline 43 & 190,62 & 92,05 & 191,50 & 91,13 & 116,70 & 20,96 & 29,12 & 7,51 & 2,72 & 18,41 & 72,40 & 7,61 & 14,90 & 36,99 & 58,93 & 69,92 & 18,72 & 0,34 & 7,49 & 29,29 & 4,95 & 75,17 & 86,70 \\
\hline 42 & 190,17 & 91,25 & 191,05 & 90,63 & 116,30 & 20,91 & 29,02 & 7,35 & 2,74 & 18,50 & 71,85 & 7,56 & 14,72 & 36,64 & 59,15 & 69,32 & 18,84 & 0,38 & 7,57 & 29,44 & 5,03 & 74,37 & 85,89 \\
\hline 41 & 189,72 & 90,45 & 190,60 & 90,13 & 115,90 & 20,86 & 28,91 & 7,19 & 2,75 & 18,58 & 71,30 & 7,51 & 14,55 & 36,29 & 59,37 & 68,72 & 18,96 & 0,41 & 7,65 & 29,58 & 5,11 & 73,57 & 85,08 \\
\hline 40 & 189,27 & 89,65 & 190,15 & 89,63 & 115,50 & 20,81 & 28,81 & 7,03 & 2,77 & 18,67 & 70,75 & 7,46 & 14,37 & 35,94 & 59,59 & 68,12 & 19,09 & 0,45 & 7,73 & 29,72 & 5,19 & 72,77 & 84,27 \\
\hline 39 & 188,82 & 88,85 & 189,70 & 89,13 & 115,10 & 20,76 & 28,71 & 6,87 & 2,79 & 18,75 & 70,20 & 7,41 & 14,20 & 35,59 & 59,81 & 67,52 & 19,21 & 0,48 & 7,81 & 29,86 & 5,27 & 71,97 & 83,46 \\
\hline 35 & 187,02 & 85,65 & 187,90 & 87,13 & 113,50 & 20,56 & 28,29 & 6,23 & 2,85 & 19,09 & 68,00 & 7,21 & 13,50 & 34,19 & 60,69 & 65,12 & 19,70 & 0,62 & 8,13 & 30,44 & 5,59 & 68,77 & 80,22 \\
\hline 34 & 186,57 & 84,85 & 187,45 & 86,63 & 113,10 & 20,51 & 28,19 & 6,07 & 2,87 & 19,18 & 67,45 & 7,16 & 13,32 & 33,84 & 60,91 & 64,52 & 19,82 & 0,66 & 8,21 & 30,58 & 5,67 & 67,97 & 79,41 \\
\hline 33 & 186,12 & 84,05 & 187,00 & 86,13 & 112,70 & 20,46 & 28,08 & 5,91 & 2,88 & 19,26 & 66,90 & 7,11 & 13,15 & $\begin{array}{r}33,49 \\
\end{array}$ & 61,13 & 63,92 & 19,94 & 0,69 & 8,29 & 30,72 & 5,75 & 67,17 & 78,60 \\
\hline 32 & 185,67 & 83,25 & 186,55 & 85,63 & 112,30 & 20,41 & 27,98 & 5,75 & 2,90 & 19,35 & 66,35 & 7,06 & 12,97 & 33,14 & 61,35 & 63,32 & 20,06 & 0,73 & 8,37 & 30,87 & 5,83 & 66,37 & 77,79 \\
\hline 31 & 185,22 & 82,45 & 186,10 & 85,13 & 111,90 & 20,36 & 27,87 & 5,59 & 2,91 & 19,43 & 65,80 & 7,01 & 12,80 & \begin{tabular}{|l|l}
32,79 \\
\end{tabular} & 61,57 & 62,72 & 20,18 & 0,76 & 8,45 & 31,01 & 5,91 & 65,57 & 76,98 \\
\hline 30 & 184,77 & 81,65 & 185,65 & 84,63 & 111,50 & 20,31 & 27,77 & 5,43 & 2,93 & 19,52 & 65,25 & 6,96 & 12,62 & 32,44 & 61,79 & 62,12 & 20,31 & 0,80 & 8,53 & 31,15 & 5,99 & 64,77 & 76,17 \\
\hline 29 & 184,32 & 80,85 & 185,20 & 84,13 & 111,10 & 20,26 & 27,67 & 5,27 & 2,95 & 19,60 & 64,70 & 6,91 & 12,45 & 32,09 & 62,01 & 61,52 & 20,43 & 0,83 & 8,61 & 31,29 & 6,07 & 63,97 & 75,36 \\
\hline 28 & 183,87 & 80,05 & 184,75 & 83,63 & 110,70 & 20,21 & 27,56 & 5,11 & 2,96 & 19,69 & 64,15 & 6,86 & 12,27 & 31,74 & 62,23 & 60,92 & 20,55 & 0,87 & 8,69 & 31,44 & 6,15 & 63,17 & 74,55 \\
\hline 27 & 183,42 & 79,25 & 184,30 & 83,13 & 110,30 & 20,16 & 27,46 & 4,95 & 2,98 & 19,77 & 63,60 & 6,81 & 12,10 & 31,39 & 62,45 & 60,32 & 20,67 & 0,90 & 8,77 & 31,58 & 6,23 & 62,37 & 73,74 \\
\hline 26 & 182,97 & 78,45 & 183,85 & 82,63 & 109,90 & 20,11 & 27,35 & 4,79 & 2,99 & 19,86 & 63,05 & 6,76 & 11,92 & 31,04 & 62,67 & 59,72 & 20,79 & 0,94 & 8,85 & 31,72 & 6,31 & 61,57 & 72,93 \\
\hline
\end{tabular}




\begin{tabular}{|c|c|c|c|c|c|c|c|c|c|c|c|c|c|c|c|c|c|c|c|c|c|c|c|}
\hline$\underline{25}$ & $\underline{182,52}$ & $\underline{77,65}$ & $\underline{183,40}$ & $\underline{82,13}$ & $\underline{109,50}$ & $\underline{20,06}$ & $\underline{27,25}$ & $\underline{4,63}$ & $\underline{3,01}$ & $\underline{19,94}$ & $\underline{62,50}$ & $\underline{6,71}$ & $\underline{11,75}$ & $\underline{30,69}$ & $\underline{62,89}$ & $\underline{59,12}$ & $\underline{20,92}$ & $\underline{0,97}$ & $\underline{8,93}$ & $\underline{31,87}$ & $\underline{6,39}$ & $\underline{60,77}$ & $\underline{72,12}$ \\
\hline 24 & 182,07 & 76,85 & 182,80 & 81,53 & 109,10 & 19,95 & 27,15 & 4,51 & 3,04 & 20,03 & 61,95 & 6,66 & 11,57 & 30,34 & 63,11 & 58,22 & 21,04 & 1,01 & 9,01 & 32,01 & 6,53 & 60,22 & 71,21 \\
\hline 23 & 181,62 & 76,05 & 182,20 & 80,93 & 108,70 & 19,85 & 27,04 & 4,39 & 3,06 & 20,11 & 61,40 & 6,61 & 11,40 & 29,99 & 63,33 & 57,32 & 21,16 & 1,04 & 9,09 & 32,15 & 6,67 & 59,67 & 70,30 \\
\hline 22 & 181,17 & 75,25 & 181,60 & 80,33 & 108,30 & 19,75 & 26,94 & 4,27 & 3,09 & 20,20 & 60,85 & 6,56 & 11,22 & 29,64 & 63,55 & 56,42 & 21,28 & 1,08 & 9,17 & 32,30 & 6,81 & 59,12 & 69,39 \\
\hline 21 & 180,72 & 74,45 & 181,00 & 79,73 & 107,90 & 19,65 & 26,83 & 4,15 & 3,12 & 20,28 & 60,30 & 6,51 & 11,05 & 29,29 & 63,77 & 55,52 & 21,40 & 1,11 & 9,25 & 32,44 & 6,95 & 58,57 & 68,48 \\
\hline 20 & 180,27 & 73,65 & 180,40 & 79,13 & 107,50 & 19,54 & 26,73 & 4,03 & 3,15 & 20,37 & 59,75 & 6,46 & 10,87 & 28,94 & 63,99 & 54,62 & 21,53 & 1,15 & 9,33 & 32,58 & 7,09 & 58,02 & 67,57 \\
\hline 19 & 179,82 & 72,85 & 179,80 & 78,53 & 107,10 & 19,44 & 26,63 & 3,91 & 3,17 & 20,45 & 59,20 & 6,41 & 10,70 & 28,59 & 64,21 & 53,72 & 21,65 & 1,18 & 9,41 & 32,72 & 7,23 & 57,47 & 66,66 \\
\hline 18 & 179,37 & 72,05 & 179,20 & 77,93 & 106,70 & 19,34 & 26,52 & 3,79 & 3,20 & 20,54 & 58,65 & 6,36 & 10,52 & 28,24 & 64,43 & 52,82 & 21,77 & 1,22 & 9,49 & 32,87 & 7,37 & 56,92 & 65,75 \\
\hline 17 & 178,92 & 71,25 & 178,60 & 77,33 & 106,30 & 19,23 & 26,42 & 3,67 & 3,23 & 20,62 & 58,10 & 6,31 & 10,35 & 27,89 & 64,65 & 51,92 & 21,89 & 1,25 & 9,57 & 33,01 & 7,51 & 56,37 & 64,84 \\
\hline 16 & 178,47 & 70,45 & 178,00 & 76,73 & 105,90 & 19,13 & 26,31 & 3,55 & 3,25 & 20,71 & 57,55 & 6,26 & 10,17 & 27,54 & 64,87 & 51,02 & 22,01 & 1,29 & 9,65 & 33,15 & 7,65 & 55,82 & 63,93 \\
\hline 15 & 178,02 & 69,65 & 177,40 & 76,13 & 105,50 & 19,03 & 26,21 & 3,43 & 3,28 & 20,79 & 57,00 & 6,21 & 10,00 & 27,19 & 65,09 & 50,12 & 22,14 & 1,32 & 9,73 & 33,30 & 7,79 & 55,27 & 63,02 \\
\hline 14 & 177,57 & 68,85 & 176,80 & 75,53 & 105,10 & 18,92 & 26,11 & 3,31 & 3,31 & 20,88 & 56,45 & 6,16 & 9,82 & 26,84 & 65,31 & 49,22 & 22,26 & 1,36 & 9,81 & 33,44 & 7,93 & 54,72 & 62,11 \\
\hline 13 & 177,12 & 68,05 & 176,20 & 74,93 & 104,70 & 18,82 & 26,00 & 3,19 & 3,33 & 20,96 & 55,90 & 6,11 & 9,65 & 26,49 & 65,53 & 48,32 & 22,38 & 1,39 & 9,89 & 33,58 & 8,07 & 54,17 & 61,20 \\
\hline 12 & 176,67 & 67,25 & 175,60 & 74,33 & 104,30 & 18,72 & 25,90 & 3,07 & 3,36 & 21,05 & 55,35 & 6,06 & 9,47 & 26,14 & 65,75 & 47,42 & 22,50 & 1,43 & 9,97 & 33,73 & 8,21 & 53,62 & 60,29 \\
\hline 11 & 176,22 & 66,45 & 175,00 & 73,73 & 103,90 & 18,62 & 25,79 & 2,95 & 3,39 & 21,13 & 54,80 & 6,01 & 9,30 & 25,79 & 65,97 & 46,52 & 22,62 & 1,46 & 10,05 & 33,87 & 8,35 & 53,07 & 59,38 \\
\hline 10 & 175,77 & 65,65 & 174,40 & 73,13 & 103,50 & 18,51 & 25,69 & 2,83 & 3,42 & 21,22 & 54,25 & 5,96 & 9,12 & 25,44 & 66,19 & 45,62 & 22,75 & 1,50 & 10,13 & 34,01 & 8,49 & 52,52 & 58,47 \\
\hline 9 & 175,32 & 64,85 & 173,80 & 72,53 & 103,10 & 18,41 & 25,59 & 2,71 & 3,44 & 21,30 & 53,70 & 5,91 & 8,95 & 25,09 & 66,41 & 44,72 & 22,87 & 1,53 & 10,21 & 34,15 & 8,63 & 51,97 & 57,56 \\
\hline 8 & 174,87 & 64,05 & 173,20 & 71,93 & 102,70 & 18,31 & 25,48 & 2,59 & 3,47 & 21,39 & 53,15 & 5,86 & 8,77 & 24,74 & 66,63 & 43,82 & 22,99 & 1,57 & 10,29 & 34,30 & 8,77 & 51,42 & 56,65 \\
\hline 7 & 174,42 & 63,25 & 172,60 & 71,33 & 102,30 & 18,20 & 25,38 & 2,47 & 3,50 & 21,47 & 52,60 & 5,81 & 8,60 & 24,39 & 66,85 & 42,92 & 23,11 & 1,60 & 10,37 & 34,44 & 8,91 & 50,87 & 55,74 \\
\hline 6 & 173,97 & 62,45 & 172,00 & 70,73 & 101,90 & 18,10 & 25,27 & 2,35 & 3,52 & 21,56 & 52,05 & 5,76 & 8,42 & 24,04 & 67,07 & 42,02 & 23,23 & 1,64 & 10,45 & 34,58 & 9,05 & 50,32 & 54,83 \\
\hline 5 & 173,52 & 61,65 & 171,40 & 70,13 & 101,50 & 18,00 & 25,17 & 2,23 & 3,55 & 21,64 & 51,50 & 5,71 & 8,25 & 23,69 & 67,29 & 41,12 & 23,36 & 1,67 & 10,53 & 34,73 & 9,19 & 49,77 & 53,92 \\
\hline 4 & 173,07 & 60,85 & 170,80 & 69,53 & 101,10 & 17,89 & 25,07 & 2,11 & 3,58 & 21,73 & 50,95 & 5,66 & 8,07 & 23,34 & 67,51 & 40,22 & 23,48 & 1,71 & 10,61 & 34,87 & 9,33 & 49,22 & 53,01 \\
\hline 3 & 172,62 & 60,05 & 170,20 & 68,93 & 100,70 & 17,79 & 24,96 & 1,99 & 3,60 & 21,81 & 50,40 & 5,61 & 7,90 & 22,99 & 67,73 & 39,32 & 23,60 & 1,74 & 10,69 & 35,01 & 9,47 & 48,67 & 52,10 \\
\hline 2 & 172,17 & 59,25 & 169,60 & 68,33 & 100,30 & 17,69 & 24,86 & 1,87 & 3,63 & 21,90 & 49,85 & 5,56 & 7,72 & 22,64 & 67,95 & 38,42 & 23,72 & 1,78 & 10,77 & 35,16 & 9,61 & 48,12 & 51,19 \\
\hline 1 & 171,72 & 58,45 & 169,00 & 67,73 & 99,90 & 17,59 & 24,75 & 1,75 & 3,66 & 21,98 & 49,30 & 5,51 & 7,55 & 22,29 & 68,17 & 37,52 & 23,84 & 1,81 & 10,85 & 35,30 & 9,75 & 47,57 & 50,28 \\
\hline
\end{tabular}




\section{REFERECENS}

[1] Akarçeşme C., Yıldıran I., Bakır A. M., Arslan Y. (2010). The realtionship among the setter position height and game results in elite women volleyball, Ovidius University Annals, Series Physical Education and Sport / Science Movement and Health, Isues 2, Romania.

[2] Kurmulis, A. (2009). Methodology for the naval sports podtokovka for the under-basketball players in R Gurcia. Dis. trud, NSA "V. Levski ", Sofia, Bulgaria.

[3] Giosheva, K., Tsarov K. (1990). System for checking, optimizing and optimizing the sporting podtokovka, VIF -

Peçatna base, Sofia, Bulgaria.

[4] Gal, Z., Ronnie, L. (2010). Vertical jump in female and male basketball players, Journal of Science and Medicine in Sport, Vol. 13(3), May., Australia, 332-339.

[5] Moreno, J.(1987). Lex Prestazione nela palacanestro. SDS, 7, Roma, Italy.

[6] Brogli A. (1991). Control of the Factors for Sports Disability. SiN, br. 8, Sofia, Bulgaria.

[7] Wainer H, Braun HI. (1988). Test validity Hillsdale NJ: Lawrence Erlbaum.

Hoffman J.R., Tenenbaum, G. (1996). Relationship Between Athletic Performance Tests and Playing Time in Elite College Basketball Players, Journal of Strength and Conditioning Research, 10(2):67-71, May., USA. 